\title{
Penerapan Cara Produksi Pangan yang Baik pada Industri Kecil Menengah (IKM) yang Telah Tersertifikasi Halal LPPOM MUI Provinsi DKI Jakarta
}

\author{
Maryam Jameelah ${ }^{1}$, Nafisah Eka Puteri ${ }^{1}$ \\ ${ }^{1}$ Program studi Teknologi Pangan, Fakultas Sains dan Teknologi, Universitas Al-Azhar indonesia, \\ Jl. Sisingamangaraja, Kompleks Masjid Agung Al Azhar, Kebayoran Baru, Jakarta Selatan 12110 \\ Penulis untuk Korespondensi/E-mail: nafisah.putri@uai.ac.id
}

Abstrak - Sertifikasi Halal suatu produk pangan tentu meningkatkan kepercayaan konsumen pada produk pangan tersebut. Akan tetapi, kriteria 'halal' tidaklah cukup jika tidak memperhatikan aspek 'thoyyib'. Masyarakat umumnya mengira bahwa pangan bersertifikat halal sebagai pangan yang 'thoyyib'. Aspek 'thoyyib' yang dimaksudkan adalah aman dikonsumsi dan telah melalui tahapan atau prosedur yang sesuai, sehingga diharapkan tidak menimbulkan efek penyakit bagi konsumen. Penelitian ini bertujuan untuk memperoleh deskripsi mengenai penerapan cara produksi pangan yang baik pada industri kecil menengah produk minuman dan bahan minuman yang telah tersertifikasi halal. Pada penelitian ini metode survei dilakukan dengan teknik purposive sampling. Data yang diamati berupa pengetahuan pemilik mengenai CPPB (Cara Produksi Pangan yang Baik) dan ketercapaian penerapan CPPB, terutama pada fasilitas sanitasi, higienitas proses produksi, serta pengawasan proses produksi. Teknik pengumpulan data dilakukan dengan wawancara dan observasi dengan bantuan kuesioner, panduan wawancara, dan lembar observasi. Data dianalisis dengan teknik analisis deskriptif melalui penyajian berbentuk grafik, tabel dan narasi. Data hubungan penerapan CPPB dan sertifikasi halal diolah menggunakan XLSTAT dengan Principal Component Analysis (PCA). Hasil analisa menunjukkan bahwa sertifikasi halal pada IKM tidak hanya mencerminkan aspek "halal" tetapi dapat pula mencerminkan aspek "thoyyib" produk yang dihasilkan. Sementara itu, tingkat pengetahuan pemilik IKM tidak dapat mencerminkan tingkat keamanan pangan yang diimplementasikan selama proses produksi. Hal ini dapat disebabkan oleh kurangnya kesadaran pemilik dan penanggungjawab IKM dan tidak adanya pengawasan oleh lembaga atau badan yang bertanggungjawab akan kulitas produk.

Abstract - Consumer trust in food products may increase with halal claims on the product. However, 'halal' is different from 'thoyyib'. People assume that halal food is 'thoyyib'. 'Thoyyib' means good to consume and health for the body. This study aimed to obtain the description of Good Manufacturing Practice (GMP) on Small and Medium Enterprises (SMEs) holding Halal certification. To gain the purpose, the purposive sampling method was applied to this research. The level of IRTP and knowledge level of GMP were observed. Data were collected by interview and observation. Data were analyzed by descriptive analysis using the graph, table, and narration. Correlation of GMP implementation and the halal claim was provided by Principal Component Analysis (PCA) using XLSTAT. Results showed that halal claims on SMEs may reflect the safety of the product. Halal-claimed food might be classified as 'thoyyib' food. However, the knowledge level of the owner can not reflect the food safety level of the product.

Keywords - CPPB, Halal Certificate, LPPOM MUI, Small and Medium Enterprises (SMEs) 


\section{PENDAHULUAN}

$\mathrm{I}^{\mathrm{r}}$ ndonesia sebagai salah satu negara dengan penduduk muslim terbesar di dunia dengan lebih dari $87 \%$ penduduk beragama Islam menjadi salah satu pangsa pasar pangan yang potensial. Hasil riset menyebutkan bahwa konsumen muslim berpengaruh signifikan terhadap laba penjualan jika mereka memperhatikan aspek halal produknya [1]. Indonesia sebagai negeri dengan angka mayoritas penduduk muslim, menjadi suatu hal yang wajar jika isu pangan halal menjadi suatu isu yang layak dikaji dan dikembangkan. Pangan halal merupakan pangan yang secara syariat diperbolehkan untuk dikonsumsi. Hal tersebut sesuai dengan ayat $\mathrm{Al}$ Qur'an pada Surat Al Baqarah (168) yang menyatakan "Hai sekalian manusia, makanlah yang halal lagi baik dari apa yang terdapat di bumi, dan janganlah kamu mengikuti langkah-langkah syaitan; karena sesungguhnya syaitan itu adalah musuh yang nyata bagimu". Pangan halal saat ini menjadi perhatian berbagai negara di dunia, mengingat semakin berkembangnya teknologi pengolahan pangan sehingga bahan yang diharamkan dapat diproses sedemikian rupa dengan cakupan penggunaan yang sangat luas. Oleh karena itu, proses sertifikasi halal menjadi suatu bentuk penegasan dan penjaminan kehalalan suatu produk pangan. Berdasarkan data pada web LPPOM MUI [2], sejak tahun 2012 hingga 2019 terdapat sebanyak 15495 SH (Sertifikat Halal) yang dikeluarkan oleh LPPOM MUI, dengan total produk yang disertifikasi sebanyak 274796.

Pangan yang telah tersertifikasi halal akan memberikan dampak keyakinan bagi konsumen akan kualitas produk yang dikonsumsi. Akan tetapi, kriteria 'halal' saja tidaklah cukup, jika tidak memperhatikan aspek 'thoyyib' atau 'sehat'. Sementara itu, stigma yang beredar di masyarakat umumnya mengelompokkan pangan halal sebagai pangan yang sudah pasti thoyyib. Aspek thoyyib yang dimaksudkan dalam pembahasan ini dikhususkan pada pemenuhan kriteria pangan yang aman untuk dikonsumsi. Mencakup tahapan atau prosedur yang sesuai, sehingga diharapkan produk yang dihasilkan tidak menimbulkan penyakit bagi konsumen.

Keamanan produk pangan menjadi suatu permasalahan global tidak hanya di negara berkembang, bahkan juga di negara maju. Permasalahan higienitas dan kondisi sanitasi banyak dikaitkan dengan keberadaan mikroba kontaminan dan pengetahuan serta sikap dari produsen [3] [4].
Proses produksi pangan yang baik perlu memperhatikan berbagai aspek. Enam prinsip higiene sanitasi makanan menyangkut kebersihan alat-alat, cara penyimpanan, cara pengolahan, cara penyimpanan dingin, cara pengangkutan, serta cara penyajian makanan [5]. Berbagai kriteria proses pengolahan pangan yang baik telah diturunkan menjadi indikator-indikator spesifik dalam Cara Produksi Pangan yang Baik (CPPB) dalam peraturan Menteri Perindustrian dengan mempertimbangkan Good Manufacturing Practice (GMP) dan Hazard Analysis and Critical Control Points (HACCP). Cara produksi pangan yang baik (CPPB) adalah pedoman yang menjelaskan bagaimana memproduksi pangan agar aman, bermutu, dan layak untuk dikonsumsi [6].

Penerapan CPPB pada industri besar menjadi suatu kriteria yang diperhatikan dan memerlukan penanganan dan pengawasan khusus. Akan tetapi, hal berbeda terjadi pada industri skala kecil hingga menegah. Umumnya pelaku usaha kurang mempertimbangkan aspek tidak nampak dan tidak berhubungan langsung dengan produk. Oleh karena itu, penelitian lebih mendalam terkait dengan aplikasi CPPB pada industri kecil dan menengah menjadi hal penting untuk dilakukan, terutama pada produk yang telah bersertifikasi halal. Tujuan dari penelitian ini adalah mendapatkan deskripsi mengenai Penerapan Cara Produksi Pangan yang Baik pada Industri Kecil Menengah dengan kategori minuman dan bahan minuman yang telah memiliki sertifikat halal.

\section{METODE}

Penelitian dilakukan terhadap IKM kategori Minuman dan Bahan Minuman di Provinsi DKI Jakarta. Penelitian dilaksanakan pada bulan Februari hingga September 2019.

Pengumpulan subjek penelitian dilakukan dengan teknik purposive sampling. Subjek adalah IKM yang telah memperoleh Sertifikasi Halal pada tahun 2018. IKM tersebut tergolong IKM yang baru pertama kali mengikuti proses sertifikasi halal (sertifikat baru) melalui program DPE (Dinas Perindustrian). Sebagai pembanding, IKM yang belum memiliki sertifikat halal juga diiikutsertakan sebagai sampel dalam penelitian ini. Teknik pengumpulan data dilakukan dengan cara wawancara dan observasi dengan bantuan kuesioner, panduan wawancara, dan lembar observasi. Berdasarkan hasil observasi, setiap IKM digolongkan ke dalam IKM level I 
hingga IV. Semakin tinggi peringkat level (level I) menandakan minimnya penyimpangan yang terjadi berkaitan dengan penerapan CPPB. Penggolongan IKM kedalam tingkatan level sesuai dengan PerKa BPOM (No. 11 tahun 2014) mengenai banyaknya jumlah penyimpangan yang dilakukan. Berdasarkan aturan tersebut setiap jenis penyimpangan dapat digolongkan termasuk kedalam jenis penyimpangan mayor, minor, serius ataupun kritis bergantung pada akibat dari penyimpangan yang dilakukan terhadap kualitas penerapan CPPB dan efeknya terhadap produk yang dihasilkan.

Data dianalisis menggunakan teknik analisis deskriptif dengan memaparkan hasil wawancara dan observasi yang disajikan dalam bentuk grafik, tabel atau narasi. Data hasil penelitian kemudian disajikan dalam bentuk tabel dan grafik. Data berupa keterkaitan CPPB dengan sertifikasi halal diolah menggunakan XLSTAT. Data diolah dengan Principal Component Analysis (PCA).

\section{HASIL DAN PEMBAHASAN}

\section{Keterkaitan Penerapan CPPB dan Sertifikat Halal pada IKM}

Sub Level IRT dari responden dalam penelitian ini dapat memberikan deskripsi umum mengenai aplikasi penerapan cara produksi pangan yang baik (CPPB). Salah satu indikator penerapan CPPB yang baik adalah dapat diaplikasikannya aspek higienitas dan sanitasi dengan baik atau minimnya penyimpangan yang ditemukan.

Berdasarkan data yang diperoleh, diketahui bahwa seluruh IKM yang belum memiliki Sertifikat Halal (SH) berada pada level 4. Hal ini menandakan IKM tersebut masih melakukan beberapa penyimpangan, baik penyimpangan Kritis, Serius, Mayor ataupun Minor. Hal berbeda ditemukan pada IKM yang sudah memiliki SH, 50\% sudah berada pada level 3, sedangkan lainnya masih ditemukan berada pada level 4 dan 1 jenis IKM sudah berada pada level 1 (Gambar 1).

\section{IKM bersertifikat halal}

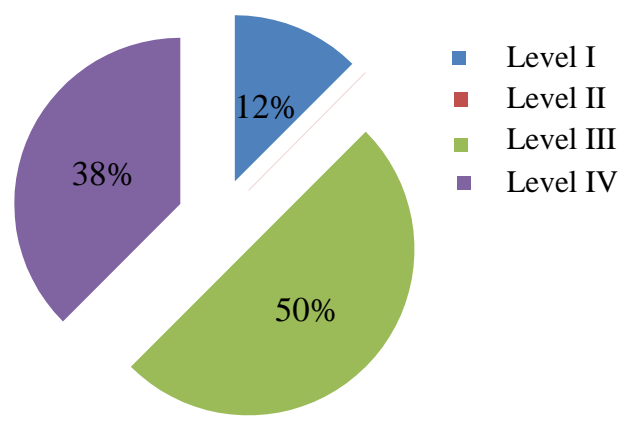

\section{IKM tak bersertifikat halal}

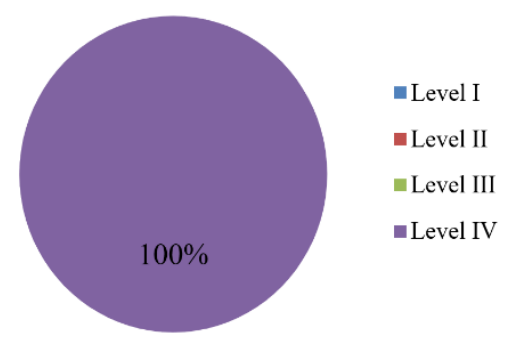

Gambar 1. Persentase level IRT

Jenis kesalahan Kritis yang dilakukan umumnya dikarenakan bahan pangan, bahan pengemas disimpan bersama-sama dengan produk akhir dalam satu ruangan penyimpanan yang kotor, lembab dan gelap atau diletakkan di lantai atau menempel ke dinding. Temuan tersebut secara langsung dapat memperbesar kemungkinan bahan pengemas atau produk akhir dirusak oleh hewan pengerat atau menyebabkan tumbuhnya jamur. Keberadaan hewan pengerat dapat berdampak serius terhadap aspek higinietas produk. Temuan tersebut terdapat pada jenis produk madu $(\mathrm{G})$ dan jamu dalam botol $(\mathrm{H})$. Tidak dilakukannya pemisahan pada berbagai bahan yang digunakan selama proses produksi dapat mempengaruhi kualitas produk karena hal ini memungkinkan terjadinya kontaminasi silang (cross contamination) dari bahan pangan yang digunakan dengan bahan pengemas. Bahan pengemas umumnya kurang diperhatikan aspek kebersihannya.

Temuan Kritis lainnya pada IKM yang sudah memiliki SH (juga ditemukan pada IKM yang belum memiliki SH) adalah tidak mempunyai penanggungjawab yang memiliki Sertifikat Penyuluh Keamanan Pangan (PKP). Temuan ini dapat mengakibatkan semakin minimnya penerapan aspek CPPB pada IKM. Adanya penanggungjawab yang sudah bersertifikat menandakan bahwa IKM tersebut sudah semakin serius dalam mempertahankan kualitas produknya dengan memperhatikan berbagai aspek yang dinilai berpotensi mencemari produk atau merusak produk yang dihasilkan.

Temuan Kritis berupa "tidak tersedia tempat pembuangan sampah tertutup" masih ditemukan pada 50\% IKM yang belum bersertifikat (juga ditemukan pada 1 IKM sudah memiliki SH). Tempat pembuangan sampah yang terbuka dapat memungkinkan munculnya lalat sebagai vektor biologis pembawa beberapa jenis penyakit. Beberapa penyakit yang dapat ditularkan melalui 
lalat adalah Salmonellosis, enteritis, bacillary disentry, cholera, dan keracunan makanan [7]. Laporan Hastutiek dan Fitri menyatakan bahwa lalat sebagai agen pembawa emerging, reemerging, dan newemerging disease karena adanya E. coli O157:H7, Cryptosporidium parvum, Helicobacter pylori, dan H5N1 [8]. Selain itu riset lainnya melaporkan beberapa jenis bakteri ditemukan di bagian luar tubuh lalat, antara lain; Proteus, Providencia, Citrobacter, Salmonella, Providencia, Escherichia, Enterobacter dan Vibrio [9]. Temuan kritis lainnya yang masih dilakukan pada kedua jenis IKM adalah "Label pangan tidak mencantumkan nama produk, daftar bahan yang digunakan, berat bersih/isi bersih, nama dan alamat IRTP, masa kedaluwarsa, kode produksi dan nomor P-IRT".

Temuan Kritis yang hanya ditemukan pada IKM belum memiliki SH antara lain; "Karyawan tidak mencuci tangan dengan bersih sewaktu memulai mengolah pangan, sesudah menangani bahan mentah, atau bahan/alat yang kotor, dan sesudah ke luar dari toilet/jamban", kondisi ini secara tidak langsung dapat menyebabkan kemungkinan kontaminasi pada produk yang berasal dari area telapak tangan pekerja.

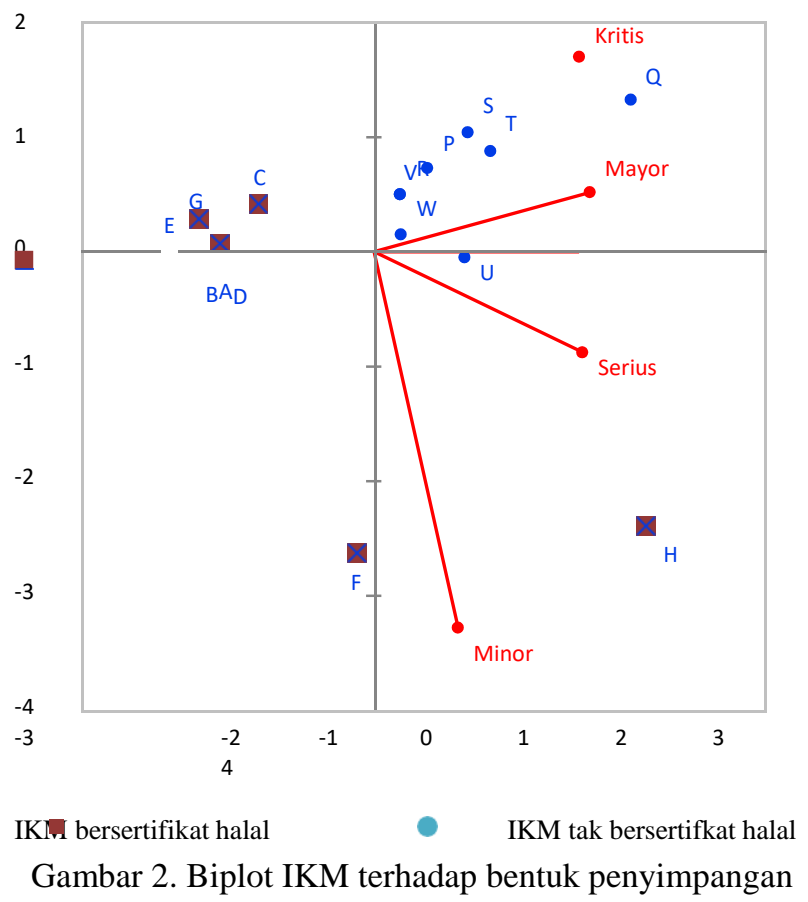

Gambar 2 merupakan biplot antara IKM dan penyimpangan yang terjadi dengan kode $\mathrm{A}, \mathrm{B}, \mathrm{C}, \mathrm{D}$, E, F, G, H sebagai IKM bersertifikat halal dan P, Q, R, S, T, U, V, W sebagai IKM tak bersertifikat halal. Penyimpangan yang terjadi terkait penyimpangan Minor, Mayor, Serius, dan Kritis terdapat pada
Kuadran I dan IV. Berdasar hasil uji Principal Component Analysis (PCA), sebagian besar IKM bersertifikat halal tidak berkorelasi atau jauh dari temuan penyimpangan, kecuali pada IKM dengan kode $\mathrm{F}$ dan $\mathrm{H}$ yang berkorelasi atau dekat dengan penyimpangan Minor dan Serius. Sementara itu, IKM tanpa sertifikat halal tampak berkorelasi dengan penyimpangan Kritis, Mayor, dan Serius.

Hal ini menunjukkan bahwa IKM bersertifikasi halal cenderung tidak banyak melakukan penyimpangan dan menerapkan Cara Produksi Pangan yang Baik dibanding IKM yang tidak memiliki Sertifikat Halal. Yang berarti bahwa sertifikasi halal pada produk pangan tidak hanya mencerminkan aspek "halal" tetapi turut mencerminkan aspek "thoyyib" meskipun produk tersebut tidak memiliki izin edar yang menjamin keamanannya. Berdasar hasil telaah ilmiah atas berbagai studi yang telah ada, dinyatakan bahwa terdapat dua konsep terkait hubungan "halal" dan "thoyyib" [10]. Pertama ialah halal dan thoyyib tidak terlepas satu sama lain, dan kedua ialah "halal" dan "thoyyib" merupakan entitas yang berbeda. Munculnya kedua konsep tersebut turut dipengaruhi oleh perbedaan standar jaminan halal di tiap negara.

\section{Pengetahuan Pemilik terkait Cara Produksi Pangan yang Baik}

Pernyataan mengenai Cara Produksi Pangan yang Baik sebanyak 40 butir diajukan kepada pemilik atau penanggungjawab IKM. Responden diminta menilai pernyataan tersebut sebagai "sangat perlu", "perlu", "ragu-ragu", "tidak perlu", atau "sangat tidak perlu". Hampir seluruh pemilik atau penanggungjawab IKM menganggap bahwa tiap pernyataan dianggap "sangat perlu" dan "perlu". Meskipun demikian, terdapat pula IKM yang menyatakan bahwa pernyataan "pintu, jendela, dan lubang angin dibuat dari bahan tahan lama, tidak mudah pecah, rata, halus, berwarna terang, dapat dibuka tutup dengan baik, dilengkapi kasa yang dapat dilepas sehingga mudah dibersihkan" adalah hal yang tidak perlukan. Jika dihubungkan dengan hasil yang berkaitan dengan temuan penyimpangan yang dilakukan oleh IKM, hal ini menunjukkan bahwa pengetahuan pemilik atau penanggungjawab IKM mengenai CPPB belum tentu diimplementasikan secara keseluruhan dalam proses produksi. Hal ini diduga akibat kurangnya kesadaran pemilik dan penanggungjawab IKM dan tidak adanya pengawasan oleh lembaga atau badan berwenang. Penelitian lainnya menyebutkan bahwa perilaku berupa penerapan CPPB dalam proses produksi dipengaruhi oleh pengetahuan, sikap, serta dukungan pemilik IKM [11]. Sementara itu, 
sebagian besar pemilik IKM memiliki peran ganda dan terlibat dalam proses produksi harian [12], sehingga hal ini menyebabkan kurang optimalnya fungsi pemantauan dan ketercapaian standar CPPB.

\section{KESIMPULAN}

Temuan penyimpangan pada IKM yang sudah memiliki SH umumnya lebih sedikit jumlahnya dan hanya ditemukan sedikit penyimpangan tipe kritis dan serius. IKM yang sudah memiliki SH sudah lebih memperhatikan aspek kebersihan yang dibutuhkan terutama ketika IKM diobservasi atau diaudit oleh tim auditor LPPOM. Sementara itu, tingkat pengetahuan pemilik IKM tidak dapat mencerminkan tingkat keamanan pangan yang diimplementasikan selama proses produksi.

\section{UCAPAN TERIMA KASIH}

Tim peneliti mengucapkan terima kasih kepada pihak Lembaga Penelitian dan Pengabdian Masyarakat (LPPM) Universitas Al-Azhar yang telah memberikan bantuan dana penelitian melalui hibah Stimulus Research Grant 2018/2019. Ucapan terima kasih kami sampaikan pula kepada pihak Dinas Perindustrian (DPE) DKI Jakarta yang telah bersedia memberikan informasi berupa data IKM yang mengikuti sertifikasi halal melalui program DPE.

\section{REFERENSI}

[1] W. M. Wan-Hasan and K. W. Awang, "Halal food in NewZealand restaurant : An exploratory study," International Journal of Economics and Management, vol. 3, no. 2, pp. 385-402, 2009.

[ 2 ] LPPOM MUI, "www.halalmui.org," [Online]. Available: https://www.halalmui.org/mui14/main/page /data-statistik-produk-halal-lppom-muiindonesia-2012-2019\# [Accessed 28 Agustus 2020].

[3] Y. Kurniadi, Z. Saam and D. Afandi, "Faktor kontaminasi bakteri E.coli pada makanan jajanan di lingkungan kantin sekolah dasar wilayah Kecamatan
Bangkinag," Jurnal Ilmu Lingkungan, vol. 7, no. 1, pp. 28-37, 2013.

[ 4 ] R. M. Hidayat, "Hubungan pengetahuan dan sikap dengan praktek higiene sanitasi penjamah makanan di rumah makan ikan dan Sleman,"seafood tipe A di Kabupaten Universitas Gadjah Mada, Yogyakarta, 2013.

[5] Suyono and Budiman, Ilmu kesehatan masyarakat dalam konteks kesehatan lingkungan, Jakarta: Buku Kedokteran EGC, 2010.

[6] [BPOM], Peraturan Kepala BPOM RI No 11 Tahun 2014 tentang Tata Cara Sertifikasi Cara Produksi Pangan Olahan yang Baik, Jakarta, 2014.

[ 7 ] H. S. Sigit, F. X. Koesharto, U. K. Hadi, D. J. Gunandini and S. Soviana, Hama Pemukiman Indonesia, Pengenalan, Biologi dan Pengendalian, Bogor: Unit Kajian Pengendalian Hama Pemukiman, 2006.

[ 8 ] P. Hastutiek and L. E. Fitri, "Potensi Musca domestica Linn sebagai vektor beberapa penyakit," Jurnal Kedokteran Brawijaya, vol. 23, no. 3, pp. 125-136, 2013.

[ 9 ] Y. P. Putri, "Keanekaragaman spesies lalat (Diptera) da bakteri pada tubuh lalat di tempat pembuangan akhir (TPA) dan pasar," Jurnal Dampak, vol. 12, no. 2, pp. 79-89, 2015.

[ 10 ] M. N. Demirci, J. M. Soon, C. A. Wallace, Positioning food safety in Halal assurance," Food Control, vol.70, pp. 257-270.

[ 11 ] N. M. A. Handayani, K. T. Adhi and D. P. Duarsa, "Factors associated with the behaviour of food handlers in the application of Good Manufacturing Practices (GMP) in the Household Food Industry (HFI) in Karangasem Food Industry," Public Health and Preventive Medicine Archive, vol. 3, no. 2, pp. 155161, 2015.

[ 12 ] I. Purwantiningrum, W. Widyhastuty, J. Christian and N. Sari, (2018, March). "Assessment of good manufacturing practice for small scale food industry in Malang region, East Java, Indonesia," In IOP Conference Series: Earth and Environmental Science, vol. 131, no. 1, p. 012028, 2018. 